\title{
Occupational class, physical workload, and musculoskeletal morbidity in the engineering industry
}

\author{
P LEINO, J HASAN, SIRKKA-LIISA KARPPI \\ From the Department of Public Health, University of Tampere, SF-33 101 Tampere, Finland
}

ABSTRACT In 1973, 502 employees in three metal industry plants, stratified by age, sex, and occupational class, were examined for physical workload by interview and observation at the workplace and for musculoskeletal disorders by questionnaire, interview, and clinical examination. Five years later, $88 \%$ of the sample were re-examined for their musculoskeletal status. The work of the blue collar groups was heavier as measured by indices of physical work load based on the observation and interview (physical strain, physical load, static phases, and stereotypy). Rheumatic symptoms, clinical findings in the musculoskeletal system, and chronic musculoskeletal diseases were more frequent in both female and male blue collar workers than in the respective white collar groups on the first occasion and the increase in morbidity during follow up was higher in the blue collar groups. At an individual level within the blue collar class, however, associations between indices of physical workload and musculoskeletal morbidity were weak or non-existent. The associations were weakened by selective movement of people with musculoskeletal disorders from heavy jobs to premature retirement or to lighter jobs. Physical strain and physical load were negatively associated with the incidence of long term musculoskeletal disorders in the female blue collar group.

Despite numerous experimental, clinical, and epidemiological studies, there exists considerable uncertainty as to the aetiological role of physical loading at work in the development of common degenerative disorders of the musculoskeletal system.

Heavy physical work and continuous or repetitive strain would seem logical sources of musculoskeletal degeneration, and several studies support that view..$^{1-6}$ There are, however, many problems associated with interpreting much of the gathered data, including the effects of selective turnover of workers, differentiation between disease causation and aggravation of symptoms, and difficulties in measuring both exposure and outcome. ${ }^{78}$ Some well designed studies seem to show only weak associations, if any, ${ }^{19-11}$ and considerable uncertainty prevails. ${ }^{1213}$

There seem to be two major difficulties in evaluating the results from many studies with respect to assessment of exposure. Firstly, numerous studies have used broad occupational titles or job categories as indirect indices of physical workload, ${ }^{314}$ without accounting for broad aetiological determinants such as social class. ${ }^{15}$ In yet other studies the information on both the loading in work and the occurrence of musculoskeletal

Accepted 7 September 1987 symptoms comes from self reports in surveys or interviews. ${ }^{16-18}$ This leaves open the possibility that the presence of musculoskeletal symptoms influences the respondents' judgment of their physical workloads and thus creates an artificial association.

We have tried to overcome some of these difficulties by estimating physical workloads in an industrial population, stratified by occupational class, by direct observation and interview at the workplace, and by assessing the state of the musculoskeletal system by both a questionnaire and a clinical examination. We have also tried to assess the presence of selection processes in this population. The study is longitudinal in the sense that it consists of two measurements in the same population, made at an interval of five years.

\section{Study sample}

The study sample was drawn from the employees of the Valmet factories in Jyväskylä, central Finland. The factories include a variety of production branches from foundry and heavy engineering to precision engineering, with the corresponding variety of work tasks.

Data were gathered by questionnaire, interviews, and a clinical examination of the musculoskeletal system in 1973 and 1978. An observation and 
Table 1 Number of subjects in the observation sample in $1973 / 8$, by occupational class and sex

\begin{tabular}{lccl}
\hline & White collar & Blue collar & Total \\
\hline Women & $94 / 87$ & $99 / 89$ & $193 / 176$ \\
Men & $103 / 89$ & $206 / 179$ & $309 / 268$ \\
Total & $197 / 176$ & $305 / 268$ & $502 / 444$ \\
\hline
\end{tabular}

interview of physical workload was carried out in 1973. A preliminary questionnaire was posted to all 4570 employees of the factories in 1971. The study population was restricted to those who had been employed by Valmet for at least 15 months on 1 February 1973. For the sampling (stratified, disproportionate, systematic) the 2653 employees were stratified into groups according to sex, age (three groups: born in 1925 or earlier, between 1926 and 1945 , or in 1946 or later) and occupational class (four groups: managers, other office staff, skilled workers, and semi-skilled workers). ${ }^{19}$ The sample thus formed consisted of 902 subjects and an observation of physical workload (see below) was carried out for 502 . The youngest age group and the managers were left outside the observation sample, as were those who had moved away from the Jyväskylä area or whose jobs were so mobile that their observation was impracticable.

Five years later 444 individuals went through the health examination again - that is, $88 \%$ of the original observed sample (table 1). In the present study the cross sectional analyses are carried out in the group of 502 , whereas the total number of subjects in the longitudinal analyses is 444 .

In the following analyses skilled and semi-skilled workers are pooled into one group called blue collar workers. The term white collar refers to the office staff.

\section{Data collection}

DIRECT ASSESSMENT OF PHYSICAL WORKLOAD The assessment of physical workload was based on a detailed observation and interview of the ergonomic characteristics of the work tasks. The observations and interviews were made in the spring of 1973 by a physiotherapist and a student of physical education. Twenty minutes per person were used for the procedure at the workplace.

The interview was made by one of the observers. The first question was "Are you at present performing your usual tasks?" An observation was carried out only in the case of a positive answer; otherwise, it was postponed to a later date. The interview included questions on the occurrence and frequency of lifting, carrying, pushing, holding up or pressing, and weight of the load or force of pushing/pressing, as well as lifting height and duration of carrying or holding up.

The observations were made according to a preformed schedule of-for example, the posture of the worker's cervical and lumbar spine, the occurrence of static muscle work or stereotypic tasks, and the occurrence of heavy or forceful work phases. ${ }^{19}$ Both observers wrote down their observations independently on precoded rating sheets and later checked the similarity of the ratings. In case of discrepancy the reasons for it were discussed by the observers, and one value agreed on. An overall index of physical strain in work was based on nine dichotomous variables: the occurrence of lifting, carrying, static phases, holding up, pressing, pushing, forceful phases, heavy phases, and stereotypic movements. The items were summed to form the ten-grade physical strain score. For the analyses in the blue collar group, the score was split into three classes $(0-2,3-4,5-9)$.

Four quantitative indices of workload were formed. Lifted load was computed according to the formula (weight lifted $\times$ lifting height $(\mathrm{cm}) \times$ frequency of lifting during the workday)/100. Carried load and sustained load were calculated according to the formula (weight carried/held up $\times$ duration of effort (sec) $x$ frequency)/3600). Pushing was stratified by used force (slight, moderate, full). The formula for pushed load was (pushing force $x$ duration of pushing $x$ frequency during the workday). The indices were logarithmised, standardised, and summed to form the physical load score. The scores were put into three classes such that those with nil load formed the first class, and the other class limits were $-3 \cdot 27-0 \cdot 359$, and 0.36-3.63 for the female blue collar workers and $-4 \cdot 75-0 \cdot 049$, and $0 \cdot 50-5 \cdot 70$ for the male group.

The static phases score was a sum index of 14 variables, each scored from 0 (never) to 2 (continuously), depicting the occurrence of static muscle work in neck and shoulders, fingers, wrists, back, ankles, and in the various muscle groups of the upper arm, lower arm, hips, and thighs. The score was classified into three classes, so that, again, those with no static phases in their work formed the first class, and the two others were $1-3,4-13$ for the blue collar women, and 1-4, 5-18 for the blue collar men.

Stereotypy is a sum index based on nine items, scored as above, depicting the occurrence of stereotypic movements in fingers, wrists, elbows, shoulders, hips, knees, ankles, and cervical and lumbar spine. Here the classification for the blue collar women was no stereotypy, 1-4, 6-10, and for the men no stereotypy, 2-3, 4-9.

Reliability of the assessment of physical work load In a random sample of 50 subjects the deviations of the observers' original ratings from the final estimate were 
calculated in the main groups of items. The mean deviation was $4.3 \%$ in the ratings of observer $A$ and $3.9 \%$ in those of observer $B$.

An estimate of the test-retest reliability of the observations was obtained from a random sample of 41 subjects reobserved three to four weeks after the main observation. The reliability of primary items describing concrete and stable features of the working environment (such as the presence of seats or tables) was high $(r=0.80-0.90)$. Lower coefficients were obtained when items subject to more rapid change, and items that at the same time were more evaluative, were considered. The reliability coefficients of the occurrence of static muscle work, by observer, were 0.60 and 0.71 (the respective kappa-coefficients were 0.35 and 0.40 ).

The reliability (internal consistency) of the scores physical strain, physical load, static phases, and stereotypy was assessed by calculating Cronbach's alpha coefficients. ${ }^{20}$ The alpha coefficient of the physical strain score was 0.73 , of the physical load score $\mathbf{0 . 9 9}$, of static phases 0.72 , and of stereotypy $0 \cdot 80$.

\section{MUSCULOSKELETAL MORBIDITY}

Preliminary data on the health status of the examinees were collected by a questionnaire that was mailed to the members of the sample at the end of January in both years. The questionnaire was completed in interviews in a health examination, during which the clinical status of the musculoskeletal system was also assessed. Every person in the sample participated in the health examination. The examinations took place during the spring, from February to June.

\section{Rheumatic symptoms}

In the questionnaire an inquiry was made about the occurrence and frequency of aches and pains in different parts of the body: "Have you suffered from aching, stiffness, tenderness, or pain in joints or muscles listed below and how often during the past year?" The list included the following items: shoulder, upper arm; elbow, forearm; wrist, hand, fingers; hip joint; thigh; knee; calf; ankle, foot; sole, toes; neck, cervical and occipital region; radiation of cervical pain to the arm; thoracic region; lumbosacral region; radiation of lumbosacral pain to the leg.

Each item was scored from 0 (never) to 3 (often or continuously). The left and right side were scored separately. Three scores were constructed. The rheumatic symptoms score is the sum of all the above items.

\section{Clinical findings}

Two trained physiotherapists performed the clinical examination of the musculoskeletal system at both stages of the study. Pains in the muscles and joints were assessed by palpation and restrictions in the movements of joints were measured. The normal values published by the American Association of Orthopedic Surgeons ${ }^{21}$ were used as standards. The findings were scored as follows:

$0=$ Symptomless

$1=$ Pain in the movement of the joint or on palpation or both

$2=$ The range of movement restricted by less than $25 \%$ of the normal range

$3=$ Restriction by 25 to $50 \%$

$4=$ Restriction by more than $50 \%$

Cervical spine:

$4=$ Restriction by more than $60^{\circ}$ and positive compression sign or foramen intervertebralis sign

Lumbosacral spine:

$4=$ Pronounced inflexibility or neurological signs in the feet (positive Laseque's or Ely's test)

Myalgies of the muscles in the hands and feet were scored from 0 (no) to 2 (bilaterally).

Twenty one variables, based on the examination, were summed to form the musculoskeletal findings score ( 80 grades).

\section{Reliability of the morbidity indices}

There was no time trend in the means of the musculoskeletal findings score either at baseline or at follow up, when the calculations were made by two week periods for the total duration of the examinations. At baseline there were no significant differences between the physiotherapists in the mean scores, similarly calculated by two week periods, but at follow up a difference was shown. At follow up, however, the distributions of the subjects by the examiners were next to equal, so that this cannot be a source of systematic error in our analyses. Fifty four subjects at baseline and 53 at follow up went through a second examination by the same physiotherapist a few days to two weeks after the first examination. At baseline, the reliability coefficient of the musculoskeletal findings score in the total sample $(n=902)$ was 0.93 in the male and 0.77 in the female group, and the kappa-coefficient 0.53 in the total follow up sample $(n=748)$.

The five year correlations of the musculoskeletal findings score varied between 0.55 and 0.64 and that of the rheumatic symptoms score between 0.57 and 0.68 in the different occupational class and sex groups.

\section{Chronic musculoskeletal diseases}

The variable chronic musculoskeletal disease was based on the questionnaire item: "Have you at present any permanent illness or impairment?" In the case of a positive response the person was asked to write down the illness(es). In the health examination interview a 
physician checked the presence of the illness, assessed its chronicity, and coded it according to a classification based on the 8th revision of the International Classification of Diseases. A dichotomous variable was formed to cover the presence or absence of one or several long term musculoskeletal diseases. The five year incidence of a chronic musculoskeletal disease was calculated in the group devoid of any such disease at baseline.

\section{SELECTION TO LIGHTER JOBS AND PREMATURE RETIREMENT}

Data on the heaviness of work histories in our sample are based on the questionnaire and interview. Each job from the beginning of working life was evaluated and its heaviness classified (descriptions of four grades from sedentary work to heavy physical work were given). ${ }^{19}$ The heaviness scores (heaviness of work $x$ time spent in it and the sum was divided by total time at work) were summed to form the index of lifetime physical strain at work. For our analysis, both the lifetime physical strain and the physical strain of 1973 were dichotomised.

Data on frequency of premature retirement by diagnostic headings are based on company records from 1961 to 1972 and are expressed as per milles of average yearly workforce.

\section{STATISTICAL METHODS}

Age adjustment of the morbidity scores was made by weighting the mean in each of three age groups (born in 1921 or earlier, between 1922 and 1933, or between 1934 and 1945) with one third. This weighting method was chosen because of the non-linearity of the age dependancy of some morbidity measures, and especially the changes in them during follow up. In testing the differences of the means in white collar and blue collar groups a two tailed $t$ test was used.

The cross sectional and longitudinal associations of the exposure and outcome variables were assessed by counting age adjusted morbidity indices in three classes of the workload variable, and testing the difference between the means in the first and the third class with a two tailed $t$ test. The dichotomous variables were also handled in this way and the means interpreted as proportions indicating prevalence or incidence of disease.

In analysing the selection to lighter jobs, and in studying the morbidity of those who had left salaried work during the follow up period, analysis of covariance with age (years) as covariate was used.

\section{Results}

Figure 1 presents the means and standard errors of the scores physical strain, physical load, static phases, and stereotypy by occupational class and sex. There were clear differences between the occupational classes in all indices of physical workload.

Figure 2(a) shows the age adjusted means of the measures of musculoskeletal morbidity, by occupational class and sex at baseline. The change in morbidity during the five year follow up is shown in fig 2(b). Morbidity was consistently higher in the blue collar than the white collar groups.

The associations between indices of physical workload and morbidity were assessed only in the blue collar groups because of insufficient variation in the exposure variables in the other groups.

Static phases showed a clear relation with both rheumatic symptoms and musculoskeletal findings at baseline, such that the greater the static muscle work the higher the mean of the morbidity score (fig $3 a$ ). In the baseline analyses with the physical load score as the exposure variable this pattern of positive association was seen in rheumatic symptoms in the male group and in musculoskeletal findings in the female group. Rheumatic symptoms in the female group and musculoskeletal findings in the male group were highest in the class with highest physical load.

The relation was less clear with physical strain as the exposure variable, with only the male workers showing higher morbidity in the class with highest strain at baseline.

In the longitudinal analyses with the static phases score as the exposure variable a positive association
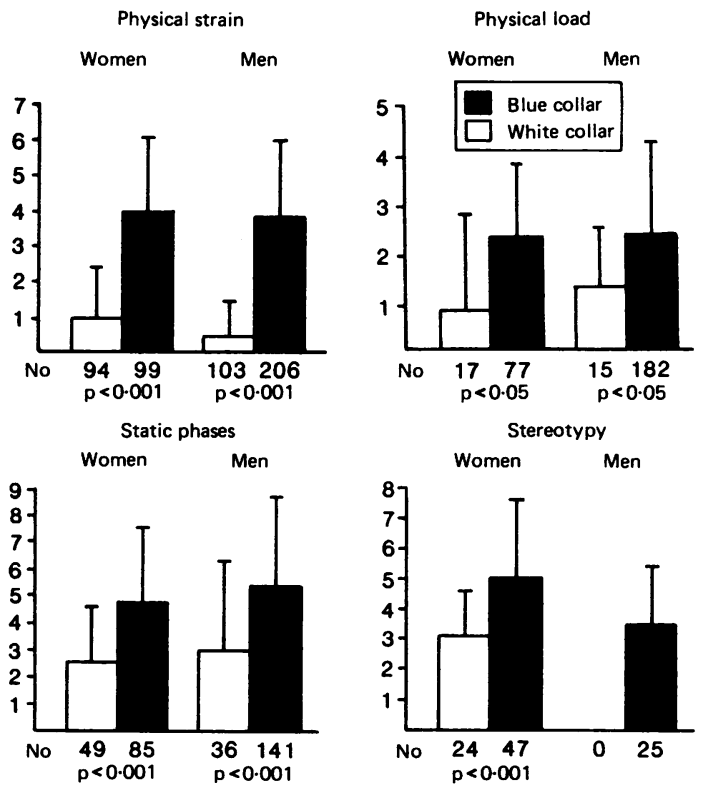

Fig 1 Physical strain, physical load, static phases, and stereotypy scores, by occupational class and sex. $\bar{x}, S D$. 
(a) Baseline
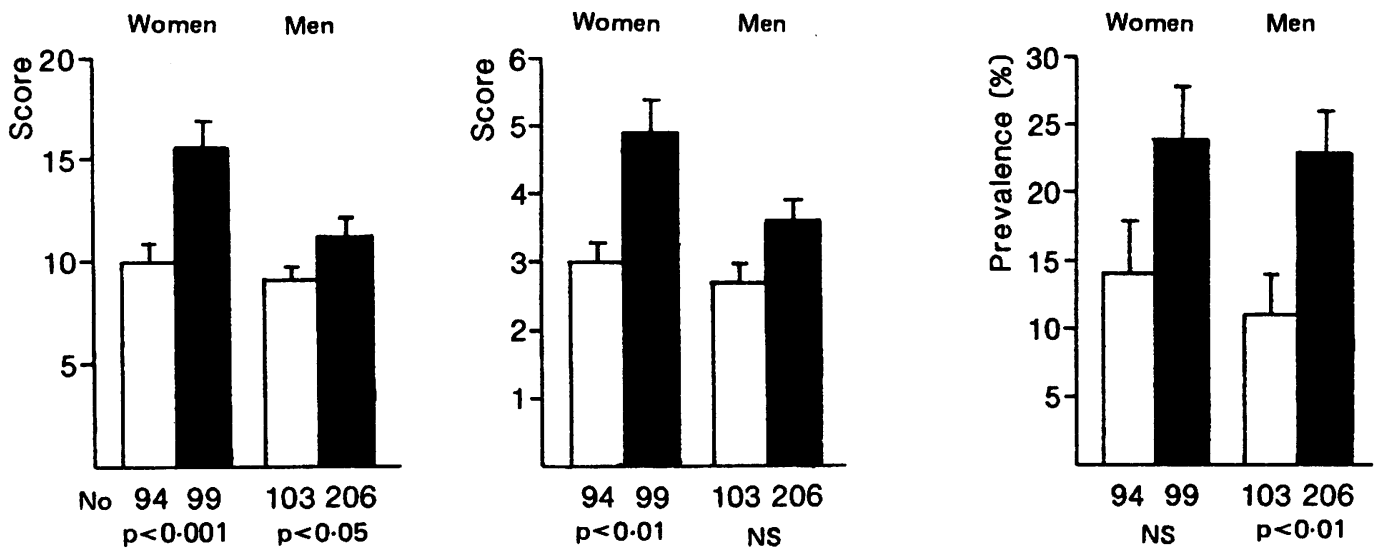

(b) Five year follow up
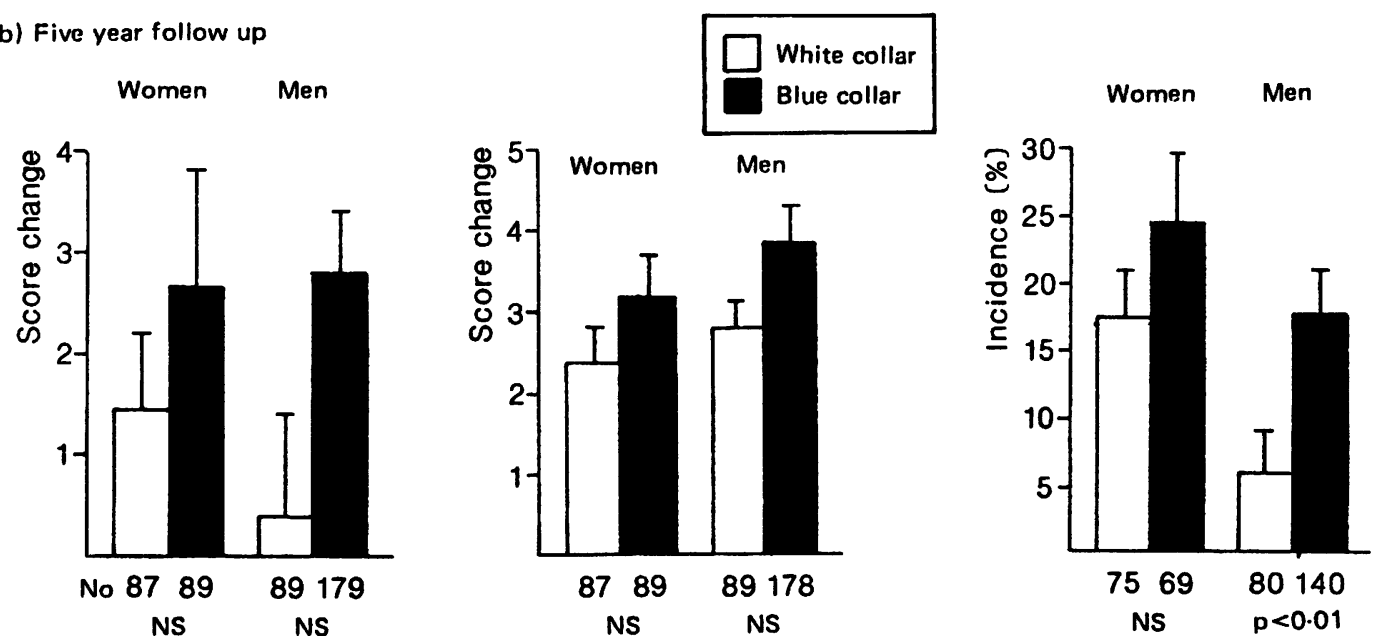

Fig 2 (a) Rheumatic symptoms and musculoskeletal findings scores and prevalence of chronic musculoskeletal disease at baseline, and (b) changes in rheumatic symptoms and musculoskeletal findings scores and incidence of chronic musculoskeletal disease during follow up, by occupational class and sex. $\bar{x}, S E(\bar{x})$.

between the exposure and the increase during the five year follow up in both morbidity scores was seen in the female blue collar workers (fig $3 b$ ). With the physical load score as the exposure, the male workers showed a similar pattern.

In the analyses with physical strain only the changes in musculoskeletal findings in the female group showed a positive association. In the remaining subanalyses in four cases of seven the increase in morbidity was highest in the class of highest work load.
The differences between the means were statistically non-significant in all analyses but one.

Stereotypy showed no association with the measures of musculoskeletal morbidity either at baseline or longitudinally.

When chronic musculoskeletal disease was used as the indicator of morbidity (fig 4), in the female group in all analyses but one there was a negative association between workload and morbidity: three were statistically significant. Little evidence for a positive 
(a) Baseline

Rheumatic symptoms

(b) Five year follow up

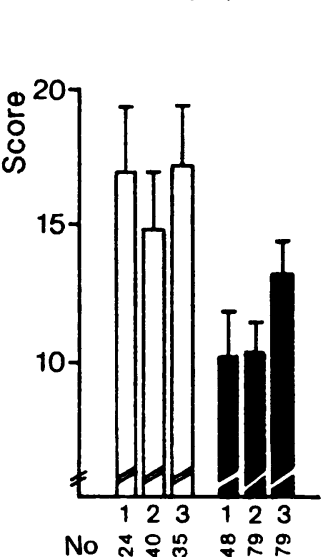

Musculoskeletal findings

Rheumatic symptoms

Musculoskeletal findings

By physical strain
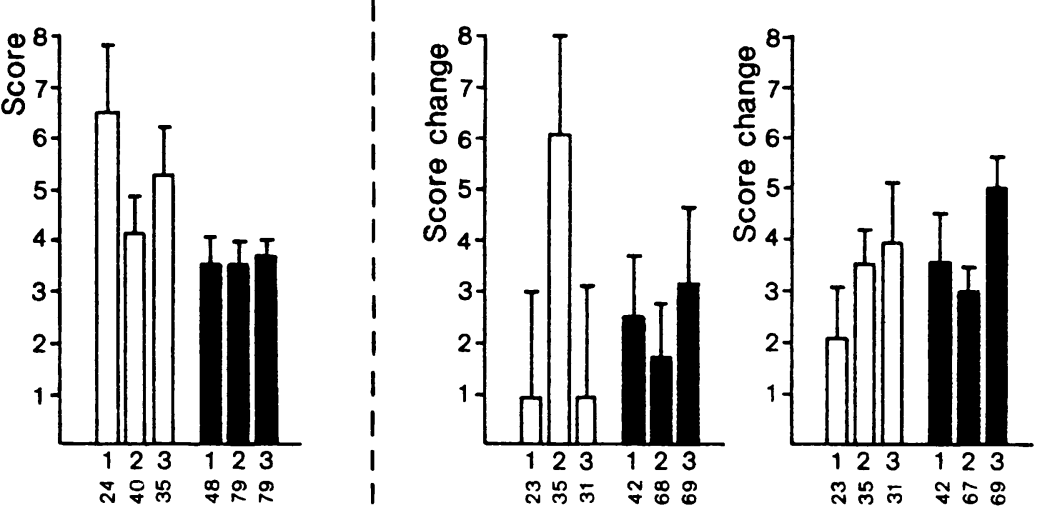

By physical load

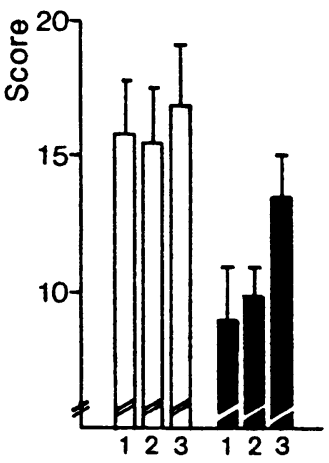

No ส
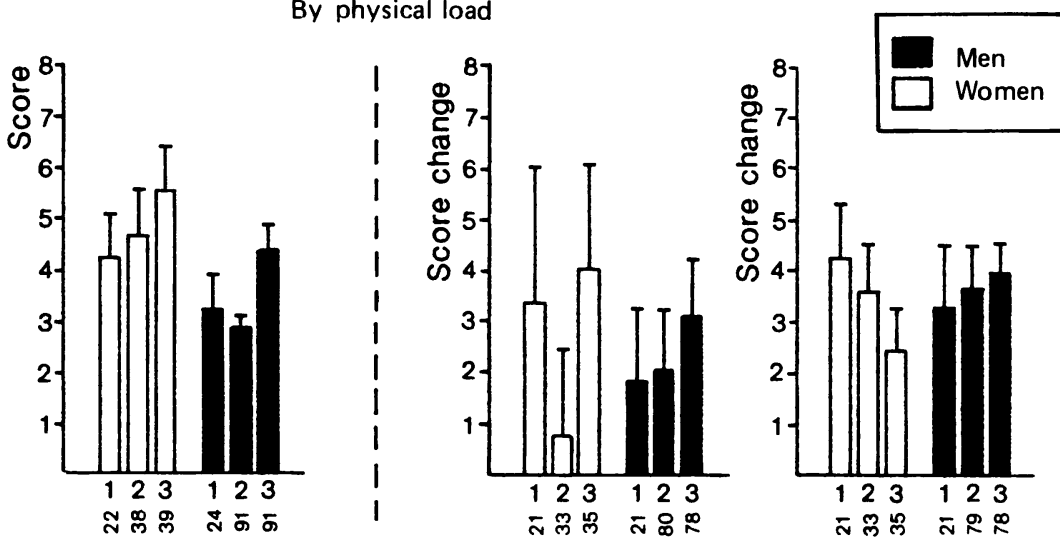

By static phases
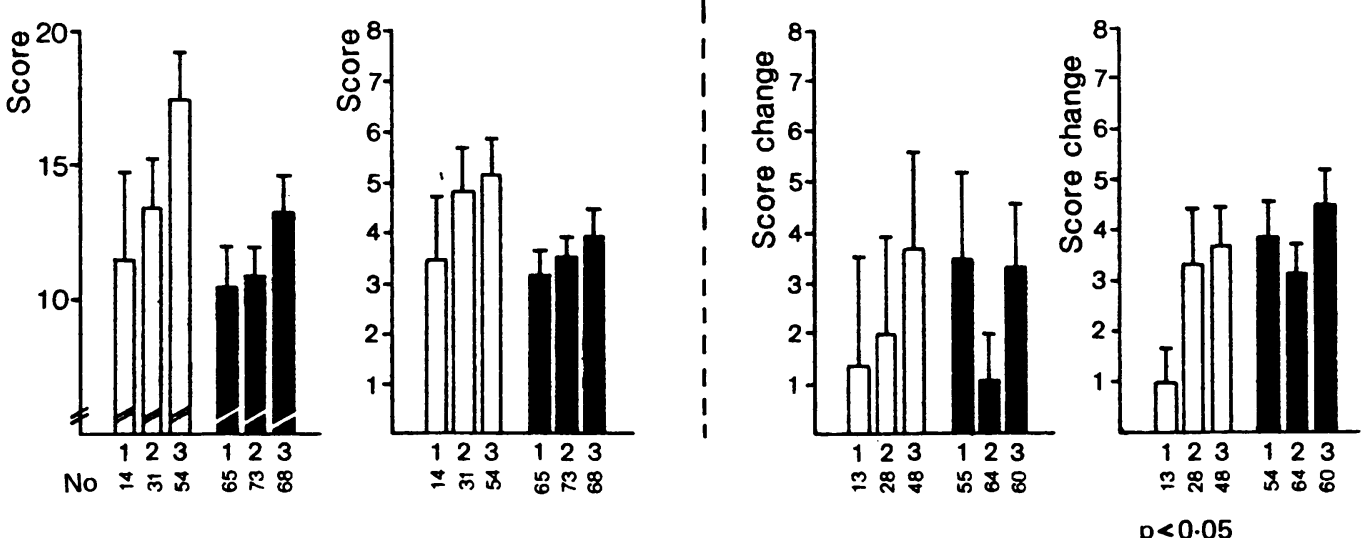

Fig 3 (a) Rheumatic symptoms and musculoskeletal findings scores at baseline, and (b) changes in scores during follow up in three classes of physical strain, physical load, and static phases scores, by sex in blue collar workers. $\bar{x}, S E(\bar{x})$. 
(a) Baseline

(b) Five year follow up
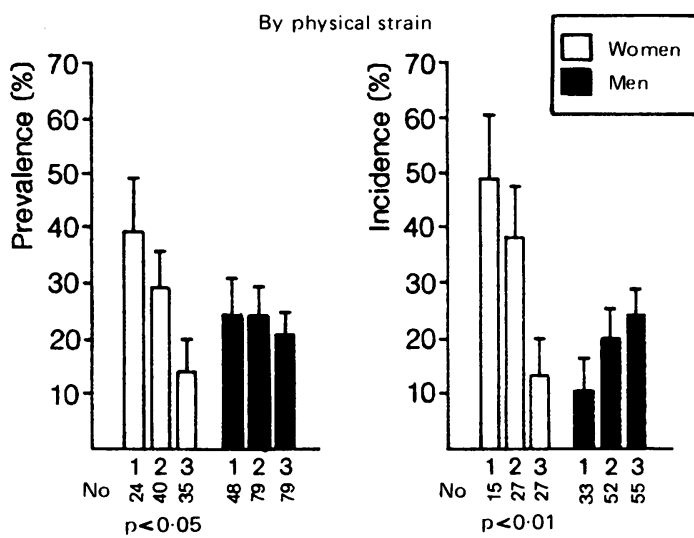

By physical load
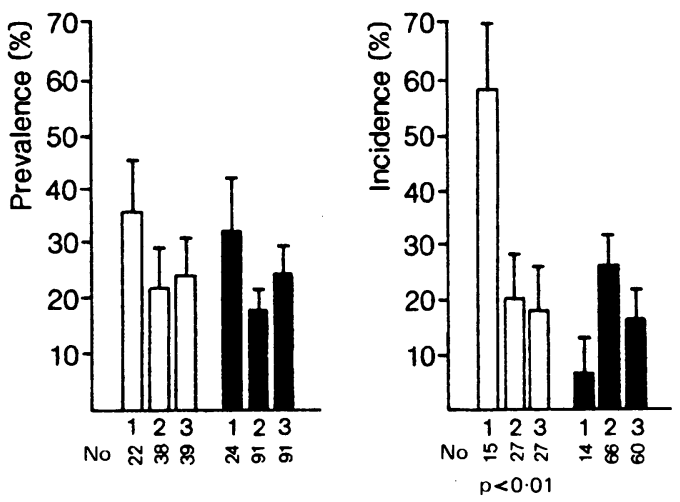

By static phases
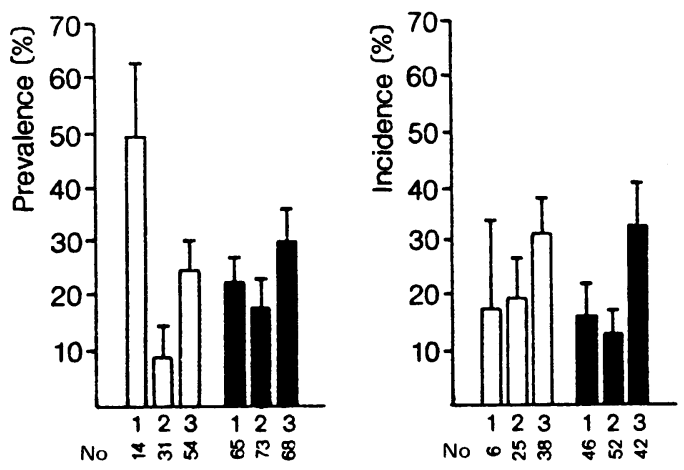

Fig 4 Prevalence of chronic musculoskeletal disease at baseline, and $(b)$ incidence of chronic musculoskeletal disease during follow up in three classes of physical strain, physical load, and static phases scores, by sex in blue collar workers. $\bar{x}, S E(\bar{x})$.
Table 2 Prevalence of chronic musculoskeletal disease in blue collar workers by lifetime physical strain in work and physical strain in 1973. (Numbers in parentheses)

\begin{tabular}{llll}
\hline & & \multicolumn{2}{l}{ Lifetime physical strain } \\
\cline { 3 - 4 } & & Low & High \\
\hline Physical strain in 1973 & Low & $0 \cdot 22(30)$ & $0 \cdot 33(42)$ \\
& High & $0 \cdot 19(54)$ & $0 \cdot 24(179)$ \\
\hline
\end{tabular}

association was found: in the male group the incidence of disease was higher the higher physical strain, and both the prevalence and the incidence of long term disease were highest in the class with most static muscle work. These associations were not significant, however.

\section{HEALTH SELECTION BEFORE SAMPLING}

Table 2 shows the age adjusted prevalences of chronic musculoskeletal disease in the blue collar workers in 1973 by lifetime physical strain and physical strain in 1973. The prevalence was highest in those who in 1973 were performing light work after having previously been employed in heavy work.

Company records from 1961 to 1972 show that premature retirement because of a musculoskeletal disease from foundry work and other heavy blue collar jobs was more frequent than from lighter blue collar or white collar jobs (table 3). The mean levels of physical strain and physical load in the respective groups of the sample from 1973 are also shown in the table. Work was heaviest in 1973 in the group where selection to premature retirement had been the most frequent and lowest where retirement had been the most infrequent.

RETIREMENT FROM WORK DURING FOLLOW UP We calculated the mean baseline workload scores of those subjects who had left salaried work during the five year period. This group was significantly older than the rest of the sample, most having retired. There

Table 3 Premature retirement owing to musculoskeletal disorders during 1961-72 (per milles of average yearly work force), and the mean physical strain and physical load scores, by sex and occupational stratum

\begin{tabular}{lllr}
\hline & $\begin{array}{l}\text { Premature } \\
\text { retirement } \\
(\%)\end{array}$ & $\begin{array}{l}\text { Physical } \\
\text { strain }\end{array}$ & $\begin{array}{l}\text { Physical } \\
\text { load }\end{array}$ \\
\hline & Men & & \\
Foundry, smithery, treating, & 2.3 & 4.9 & 1.1 \\
etc & 1.5 & 3.7 & -0.2 \\
$\begin{array}{l}\text { Other blue collar } \\
\text { White collar }\end{array}$ & 0.8 & 0.6 & -0.9 \\
& Women & & \\
Foundry, smithery, treating, & 8.1 & 4.6 & 0.5 \\
etc $\begin{array}{ll}\text { Other blue collar } \\
\text { White collar }\end{array}$ & 4.5 & 3.9 & 0.3 \\
\hline & 1.0 & 1.0 & -1.6 \\
\hline
\end{tabular}


were no significant differences between the means of any workload scores in this group and in the rest of the sample who were followed up, either in the 47 blue collar workers or in the 25 white collar staff. The age adjusted morbidity in this group at baseline did not differ significantly from those in the rest of the follow up sample. Neither did the changes in morbidity during the follow up period differ between the groups.

\section{LOSS TO FOLLOW UP}

Altogether, 58 workers ( 21 white collar, 37 blue collar) were lost to follow up. In the blue collar workers the mean physical strain, physical load, and static phases scores of those lost to follow up did not differ significantly from the mean indices in the group followed up. The mean stereotypy score of those lost to follow up was lower than that of those followed up. In the baseline morbidity scores there were no significant differences between the two groups. In the white collar staff the workload or baseline morbidity did not differ between the two groups.

\section{Discussion}

We found a clear difference in both exposure and outcome between the white collar and blue collar groups in our sample. The work of the female and male blue collar workers was more strenuous and their morbidity higher than those of the respective white collar groups in all indices of musculoskeletal morbidity-frequency of symptoms, amount of clinical findings, and long term disorders. The difference in morbidity was evident both in the baseline cross sectional study and in the mean changes of morbidity scores during the five year follow up.

The association of strain at work and musculoskeletal morbidity at an individual level within the blue collar worker group was less consistent, however. On the whole, the static phases score seemed to have the most consistent positive association with musculoskeletal morbidity, whichever outcome measure was used. Also the physical load score, especially in the male group, showed a positive association with the rheumatic symptoms and the musculoskeletal findings scores but not with the chronic diseases. The association of physical strain with musculoskeletal symptoms and findings was less convincing, and stereotypy showed no association at all.

Interestingly, in the female blue collar workers the prevalence and incidence of long term musculoskeletal diseases were negatively associated with physical strain and physical load. Also the prevalence in the class of nil static phases was higher than in the other classes of the variable.
METHODOLOGICAL CONSIDERATIONS

The weakness and inconsistency of observed associations between strain at work and morbidity may result from at least three possible features in our study. Firstly, this may simply reflect the inadequacy of our instruments for measuring either the physical workloads or musculoskeletal morbidity or both. Secondly, the weakness of association may result from insufficient variation in the physical loads studied, and, finally, it may truly represent the phenomena studied.

Our method of measuring ergonomically relevant workloads was based on a structured observation and interview schedule with dichotomous (presence or absence of type of load) and continuous (weight or force/duration/frequency) rating scales. Such a method seems in principle to be the best available for assessing simultaneously several ergonomically relevant aspects of a complex work performance.

We tried to enhance the reliability of the measurement by having two independent observers rate all the jobs and by combining their results, after mutual consultation, into single scores. The observations, nevertheless, were only 20 minute samples of much longer working periods in which tasks could vary with unknown frequency. The sampling period was a choice of economic and logistic necessity. The interview which was included in the assessment of physical workload probably enhanced the reliability of the method. That there was considerable variation, at least within the course of several weeks, in the ergonomic characteristics of the jobs is shown by the fact that, despite a good interobserver consistency of the observation method, its overall test-retest reliability was rather poor.

One may question the appropriateness of the physical strain score as it gives equal weight to rather different types of ergonomic drawbacks. We wanted, however, to use both a general index built simply by counting the number of drawbacks and indices of more specific types of loading.

The reliability of the indices of musculoskeletal morbidity is as satisfactory as can be expected of a standardised clinical method of questioning and examining.

Even if we cannot estimate this with precision it seems that our methods of measuring both physical working loads and musculoskeletal morbidity are adequate to show at least moderate associations between the two.

No association between the study variables would, obviously, appear if the physical workloads studied varied only within a restricted range. The jobs varied, however, from completely sedentary ones (office paper work or assembly of electric meters for example) to those involving vigorous muscle activity (such as 
foundry work). Both the load and the strain score varied over a wide range (fig 1). In direct measurements of oxygen consumption in this same population energy expenditure was found to vary over an almost sixfold range. ${ }^{22}$

\section{HEALTH SELECTION}

Our results show that before the sampling there had been selection forces at work that would tend to dilute the associations between heavy physical work and musculoskeletal morbidity in our population. People have been moved to lighter jobs or taken premature retirement because of, among other things, musculoskeletal problems. In the analysis of the prevalence of chronic musculoskeletal disease by lifetime physical strain and physical strain in 1973, the prevalence was high in those who had always been in heavy work, and in those who had moved from heavy to lighter work. This overrepresentation of chronically ill subjects in the latter group we take to point to a selection process transferring people from heavy work to lighter ones because of a musculoskeletal disease.

Of the processes mentioned above, selection to lighter work because of a musculoskeletal disease, as well as a disease hindering the adoption of a heavy job, are primarily operating within the occupational classes. They may be reasons for the difference in strength of associations in the results on group level, on the one hand, and on an individual level on the other, for work changes over the white collar-blue collar boundary are few. Selection to premature retirement dilutes associations both at individual and at group level.

The negative association in the female blue collar group between the indices of physical workload and prevalence of chronic musculoskeletal disease may also be produced by health selection: chronically ill people do not enter a heavy occupation and those who contract a chronic disease must leave heavy work.

We have no satisfactory explanation for the finding that even the incidence of long term musculoskeletal disease in those who had no such disease at baseline was highest in the class of lowest physical strain and physical load. It certainly illustrates the fact that work is but one factor of many in the aetiology of musculoskeletal disorders. ${ }^{23}$ Even the lighter work, however, as measured by our indices in the female blue collar group may be strenuous in its monotony. repetitiveness compared with the same classes in male workers. The variable chronic musculoskeletal disease also differs from the other two outcome measures used in that a subject's consciousness of her existing diagnosis, on which the variable was based, is dependent on a prior physician's consultation. The frequency of usage of health services, on the other hand, is more frequent the higher the social strata, which continuum exists even within the blue collar workers.

WAY OF LIFE OF THE OCCUPATIONAL CLASSES

We thus arrive at the conclusion that, if the gross nature of work performed (manual or non-manual) is accounted for, the association between physical workload and musculoskeletal morbidity is weak. Does this mean that physical labour is an insignificant source of musculoskeletal derangements? We do not think so. We believe that the main effect of physical work is apparent in the difference in morbidity between the occupational classes. The white and blue collar occupational classes in our study were exposed to quite different levels of physical load and strain in their work. Among a host of other factors affecting the morbidity of the blue collar workers, we believe that the higher physical working loads that they are exposed to contribute importantly to the higher prevalence and incidence of musculoskeletal disorders in this group.

The occupational classes studied here represent broad social classes in an industrial society in the beginning of the 1970s. The social class differentials in general morbidity and mortality are well known and their causes have recently been much discussed. ${ }^{24} 25$ It seems obvious that no single explanation of these differentials is likely to emerge but that they are caused by differences in a whole range of factors in the living conditions, including working conditions, and health habits of the classes.

Apart from the working conditions, numerous other features in the daily life, past and present, of the occupational classes studied differ. Most of the blue collar workers in our sample have moved from the countryside to the town to become industrial workers. Their mode of leisure time. activities differs widely from and includes more physical exertion than that of the white collar group, their housing conditions are poorer, and they generally live farther from their workplace than the white collar staff, etc. ${ }^{26}$ These factors are inseparably intertwined with the physical workloads in the aetiology of musculoskeletal disorders.

\section{References}

1 Anderson JAD. Rheumatism in industry: a review. $\mathrm{Br} \mathrm{J}$ Ind Med 1971;28:103-21.

2 Hettinger T. Occupational hazards associated with diseases of the skeletal system. Ergonomics 1985;28:69-75.

3 Wickström G. Effect of work on degenerative back disease: a review. Scand J Work Environ Health 1978;4, suppl 1:1-12.

4 Waris P. Occupational cervicobrachial syndromes: a review. Scand $J$ Work Environ Health 1979;5, suppl 3:3-14.

5 Kilbom $\AA$, Persson J, Jonsson BG. Disorders of the cervicobrachial region among female workers in the electronics industry. International Journal of Industrial Ergonomics 
1986;1:37-47.

6 Silverstein BA, Fine LJ, Armstrong TJ. Hand wrist cumulative trauma disorders in industry. Br J Ind Med 1986;43:779-84.

7 Hernberg S. Work-related diseases-some problems in study design. Scand J Work Environ Health 1984;10:367-72.

8 Koskela R-S, Kolari PJ, Järvinen E, Korhonen H. Completeness of occupational history and occurrences of work-related diseases. Scand J Work Environ Health 1984;10:455-9.

9 Anderson JAD. Arthrosis and its relation to work. Scand J Work Environ Health 1984;10:429-33.

10 Kuorinka I, Koskinen P. Occupational rheumatic diseases and upper limb strain in manual jobs in a light mechanical industry. Scand J Work Environ Health 1979;5, suppl 3:39-47.

11 Luopajärvi T, Kuorinka I, Virolainen M, Holmberg $\mathbf{M}$. Prevalence of tenosynovitis and other injuries of the upper extremities in repetitive work. Scand J Work Environ Health 1979;5, suppl 3:48-55.

12 Andersson $G$. Low back pain in industry: epidemiological aspects. Scand J Rehabil Med 1979;11:163-8.

13 Valkenburg HA, Haanen HCM. The epidemiology of low back pain. In: White AA, Gordon SL, eds. Symposium on idiopathic low back pain, Miami, 1980. St Louis: CV Mosby Company, 1982:9-22.

14 Lawrence JS. Rheumatism in populations. London: William Heinemann Medical Books, 1977.

15 Cobb S. The frequency of rheumatic diseases. Cambridge: Harvard University Press, 1971.

16 Magora A. Investigation of the relationship between low back pain and occupation. IV. Physical requirements: bending, rotation, reaching and sudden maximal effort. Scand $J$ Rehabil Med 1973;5:186-90.

17 Svensson H-O, Andersson GBJ. Low back pain in 40- to 47-year old men: work history and work environmental factors. Spine 1983;8:272-6.

18 Damkot DK, Pope MH, Lord J, Frymoyer JW. The relationship between work history, work environment and low back pain in men. Spine 1984;9:395-9.

19 METELI. Terveystutkimus. Otanta, menetelmät ja toteuttaminen. Jyväskylä: Liikunnan ja kansanterveyden julkaisuja, 1975. (With English summary.)

20 Sonquist JA, Dunkelberg WC. Survey opinion research: procedures for processing and analysis. Englewood Cliffs: Prentice-Hall Inc, 1977.

21 American Academy of Orthopedic Surgeons. Joint motionmethod of measuring and recording. Chicago: AAOS, 1965.

22 Aunola R, Nykyri R, Rusko H. Strain of employees in the machine industry in Finland. Ergonomics 1978;21:509-19.

23 Troup JDG. Causes, prediction and prevention of back pain at work. Scand J Work Environ Health 1984;10:419-28.

24 Townsend P, Davidson N. Inequalities in health: the Black report. Harmondsworth: Penguin, 1982.

25 Whitehead M. The health divide: inequalities in health in the 1980s. London: Health Education Council, 1987.

26 Hasan J. Way-of-life, stress, and differences in morbidity between occupational classes. In: Fox AJ, ed. Inequalities in health within Europe. Aldershot: Gower Press (in press). 